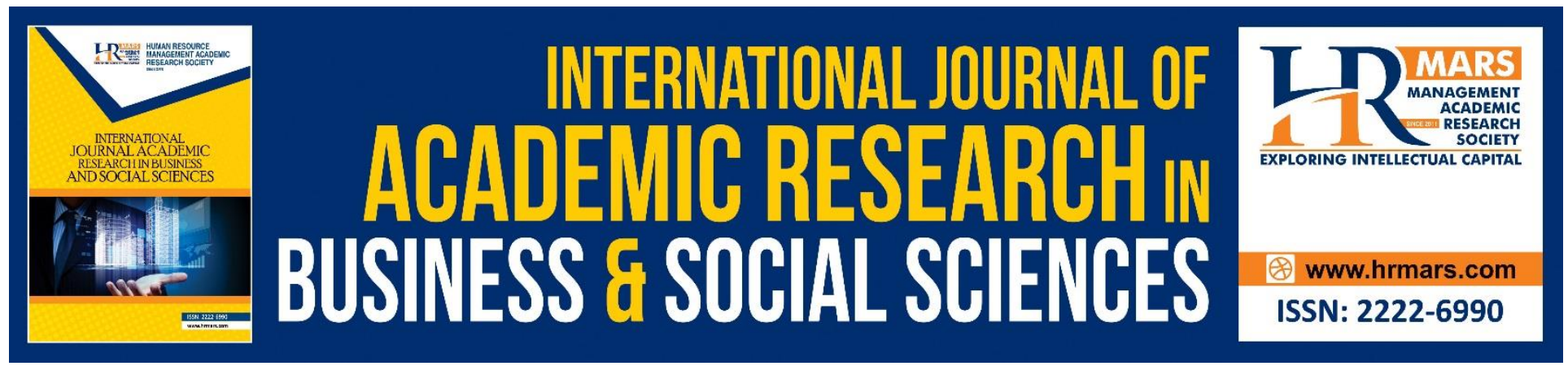

\title{
Diversity and Ethical Issues in the Organizations
}

\section{Tamunomiebi, Miebaka Dagogo lyioriobhe Ezekiel Ehior}

To Link this Article: http://dx.doi.org/10.6007/IJARBSS/v9-i2/5620

DOI: $\quad 10.6007 /$ IJARBSS/v9-i2/5620

Received: 21 Jan 2019, Revised: 19 Feb 2019, Accepted: 07 March 2019

Published Online: 09 March 2019

In-Text Citation: (Tamunomiebi \& Ehior, 2019)

To Cite this Article: Tamunomiebi, M. D., \& Ehior, I. E. (2019). Diversity and Ethical Issues in the Organizations. International Journal of Academic Research in Business and Social Sciences, 9(2), 839-864.

\section{Copyright: (C) 2019 The Author(s)}

Published by Human Resource Management Academic Research Society (www.hrmars.com)

This article is published under the Creative Commons Attribution (CC BY 4.0) license. Anyone may reproduce, distribute, translate and create derivative works of this article (for both commercial and non-commercial purposes), subject to full attribution to the original publication and authors. The full terms of this license may be seen at: http://creativecommons.org/licences/by/4.0/legalcode

Vol. 9, No. 2, 2019, Pg. 839 - 864

Full Terms \& Conditions of access and use can be found at http://hrmars.com/index.php/pages/detail/publication-ethics 


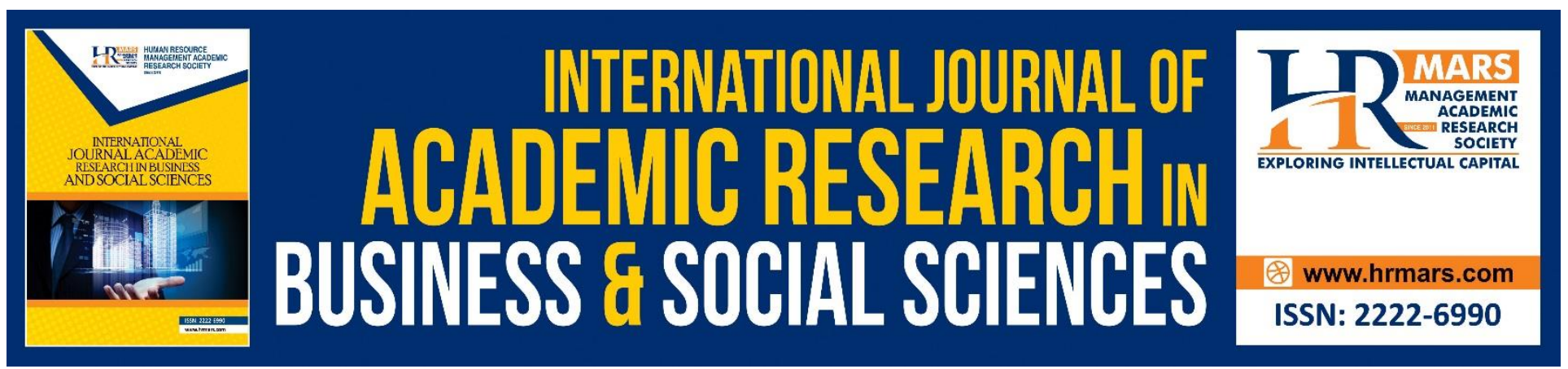

\title{
Diversity and Ethical Issues in the Organizations
}

\author{
Tamunomiebi, Miebaka Dagogo \\ Department of Management, Faculty of Management Sciences, Rivers, State University, \\ Nkpolu-Oroworukwo, PMB 5080, Port Harcourt, Nigeria.

\section{lyioriobhe Ezekiel Ehior} \\ Doctoral Candidate Department of Management, Faculty of Management Sciences, Rivers State \\ University, Nkpolu- Oroworukwo, PMB 5080, Port Harcourt, Nigeria.
}

\begin{abstract}
Diversity and ethics are component of every society and they are major challenge that has turned into a losing situation for all involved, leading to demoralization of organization. No doubt many believe societal diversity and ethics are the fundamental for organizational efficiency when properly managed. In every organization, there are diverse beliefs, culture, religion, age, gender and educational background among employees, manager and executives in organizations need to know what are the most ethically appropriate or inappropriate courses of actions to take in their daily workplace situations. Diversity is the ways people differ in an organization which can affect task or relationship of the employees. While ethics is the study of moral obligation, or separating right from wrong and includes acts such as ethical decisions and social responsibility acts. The focus of this study is on diversity and ethical issues in an organization. This research work is a descriptive study in nature. The secondary information have been collected from different scholars' and researchers' published books, articles published in different journals, periodicals, conference paper, working paper and website which examine literature in the area of organizational diversity and ethics. I will therefore recommend that management must modify their styles to manage diversity and ethics in the organization. It is also important that management assess the current level of diversity within the organization beginning with culture, ethnicity and education. Management should adopt a high diversity culture for continuous change and improvement in the organization.
\end{abstract}

Keywords: Diversity and Ethics, Education, Ethnicity, Culture, Ethical Decision.

\section{Introduction}

The effective organization has integrating devices consistent that the diversity and ethics of its environment. The more diverse the environment and the more the organization, the more elaborate the integrating devices. Organizations developed from the society which is made up of people with different diversity and ethics. These people which are the vital resource of an organization, need to 
be manage by the organization for effective performance of organization. The effective managing of people of different diversity and ethics in the organization, determined the success of an organization. An organization is a group of people working towards a common objective, or set of objectives (Thom-Otuya, \& Ubulom, 2002).

The most important factor in any organization is the human element. We cannot therefore, talk about diversity in an organizations, without human beings. What makes an organization to survive is due to the activities of the various units by people. It follows, therefore, that organizations are systems of human beings whose activities are interdependent (Johnnie, 1988). De Paula (1967), believes that the structure of organizations' designed without human activities are mere skeleton. It is human beings that breathe life into the organization and brings about profitable exploration of its activities. People of diverse culture and ethnicity, came into the organization with different behavior, personality and motivation. The behavior of members of an organization directly affects both the structure, performance and functioning of the organization.

There are many environmental trends affecting organizations in recent years which are the rapidly changing composition of the workforce. Societal diversity and ethics is said to be responsible for all manner of positive and negative ills of an organization. In every organization, diversity and ethics practices are important to most organizations who want to gain the loyalty of employees and trust of consumers. Ethics training is becoming an increasingly popular trend in organization helping to align staff efforts with the organization's broader vision.

Nigeria is often regarded as one of the most populous industrially developing nations in the world and richly blessed with abundant human and natural resources. However, there are different diversity and ethic. Issues among the people that are vital resources to an organization which need to be managed by the management of an organization. No matter the type of organizations, chances are that people's actions, inactions or counteractions could be a threat to its corporate performance, existence and ultimate survival.

Carrell, (2006) viewed diversity in the society as the ways people differ in an organization which can affect task or relationship of the employees. People can be differ in area of education, culture, religion, belief and ethnicity. In other words, diversity is the similarities and differences among employees in the society as well as an organization. It has been opined that many modern organizations hire employees from diverse countries, cultures, and people of different values and life styles. While employees expect returns from the organization, their effective performance is significant for its success. It is therefore important to consider the effect of diversity in the society on organizational output. Diversity among employees in the organization could present tremendous challenges as well as opportunities to the organization in terms of effective management.

Understanding of diversity will enable organizations to solve problems and improve performance. Diversity issues are now considered important and are projected to become even more important in the future due to increasing differences in the population of many countries like Nigeria. Organizations need to focus on diversity and look for ways to become totally inclusive organizations 
because diversity has the potential of yielding greater productivity and competitive advantages. Managing and valuing diversity is a key component of effective people management, which can improve workplace productivity. Diversity can increase productivity of an organization when properly managed and also improve effectiveness and efficiency. Unmanaged diversity in the workplace can cause obstacle for achieving organizational goals. Therefore, diversity can be perceived as a doubleedged sword in an academic context, diversity encompasses different dimensions including ethnic groups, language, color, attitude, values, culture, education, belief and religion (Rau \& Hyland, 2003). Diversity management practices enhance performance, effectiveness and efficiency of organization.

Hofestede, (2003) revealed that diversity and ethics among the people in the organization promotes creativity, innovation and problem solving, efficiency and effectiveness. This means the sharing of different ideas and perspectives. Kanter, (2006) found that innovative organizations deliberately used heterogeneous teams to solve problems and they employed more women and people of color than less innovative companies. This is because diverse groups possessed a broader base of experience and perspectives (Kreitner \& Kinichi, 2004)

Ethics are the rules of moral values that guide decision making by groups and individuals. They are a person's fundamental orientation towards life - what he or she sees as right and wrong. Ethical responsibilities of a business encompass how the organization's decision and actions show concern for what its stakeholders (employees, customers, stockholders and the community) consider fair and just. Ethical behavior involves knowing what is right and wrong and behaving accordingly. Behaving ethically can contribute to the success in the society as well as an organization. Ethics requires people's proper relations with one another, how should people treat others? What responsibility should they feel for others?

Virtually, all cultures in the society agree that basic moral values like integrity, respect for human life, self-control, courage and self-sacrifice are right; cheating, cowardice and cruelty are wrong. All of the world's major religions support a version of the Golden Rule, even it is only in the negative form: Do not do unto others as you would not have them do unto you.

Organizations aim to achieve prosperity, growth and survival. Ideally, success should benefit all the stakeholders in the organization - owners, management, employees, customers and suppliers, but the single-minded pursuit of organization objectives can act to the detriment of employees' wellbeing and security. There may be a tension between accomplishing business purposes and the social and ethical obligations of an organization to its employees. The chances of attaining a good climate of employee relations are slight if no attempt is made to recognize and act on an organization's duties to its members.

Diversity and ethics in the workplace strives to make people of all socio-economic background feel comfortable working within the organization. It further promotes equal opportunities among all employees or prospective employees to be hired and promoted based on merit not race, gender or creed. A small organization diversity program maintains non-discrimination standards and enforces 
penalties for non-compliance. Beyond the legal compliance issues explored in workplace diversity, organizations can benefit from encouraging more than just tolerance but also an embrace of differences. In doing so, new horizons can be opened with new customer demographics, business partners and internal performance methods. Even a small organization is exposed to many different cultures; ethnicity and education levels and can improve future organization opportunities by managing diversity and ethics in the workplace.

The main contribution to knowledge from this research will be the positioning of knowledge with regard to diversity and ethical issues within the organization as well as the behavior of the people. The framework will highlight strategies on how diversity and ethics are perceived at different levels in an organization and how employees and managers' views differ. When societal diversity and ethics are unmanaged in an organization, there will be obstacle in achieving organizational predetermined goals which will lead to poor organizational performance.

Against the background of the issues raised, this study attempts to achieve the following objectives, the concept of diversity, the elements of diversity, and diversity management in an organization. The concept of ethics in organization will be discussed. The benefits derived from ethical behavior in an organization will be look into. The study will also look at ethical values in organizations as well as ethical and organization strategy. Making decision about ethical issues in an organization will equally be discussed. Finally, ethical issues in diversity management as well as conclusion on the issues of diversity and ethics in the organization will be established and recommendation will be made.

\section{Concept of Diversity}

Organizations are establish from the society and the society is made up of people who move into organization to resource raw materials from the society and transform the raw material into finished goods and services for the society. This people from different diversity and ethics in the society, work together in an organization to achieve a common goal. The managers need to cope with their various diversity and maintain good ethics, so that organizational predetermined goal can be achieved. However, diversity is becoming more common in today's global business climate. In this era of economic globalization, many companies are making efforts to cope with diversity, which aims to employ workers from different backgrounds to provide tangible and intangible benefits to the organization with a competitive edge. This can include employing workers with cultural and language skills that can lead to greater reach for the business. Diversity experts believe that heterogeneous groups can contribute more creative ideas to the mix. Employers can offer more solutions to customers because of new ideas and processes brought into the organization. Diversity increase employees' morale and causes employees to desire to work more effectively and efficiently. Diversity in leadership within a firm allows managers to bring in new skills and methods for achieving unity within their teams.

Diversity increases creativity within an organization because heterogeneous groups are crossfertilizing one another within the organization. According to Ethno Connect, a consulting company specializing in diversity, employees from different backgrounds bring in a variety of solutions on how 
to achieve a common goal. As more diverse ideas are suggested, the chances of finding a workable answer are improved. In atmospheres when brainstorming is necessary, more ideas are formed because team members are culturally diverse. Companies that plan to expand into global markets benefit from language diversity in the workplace. For example, a company with employees fluent in Japanese and who understands Japanese culture experience an easier time communicating with representatives from Japan. Many bilingual workers experience an advantage when applying for jobs because employees understand the benefits of language diversity. An increased presence usually results in an increase in sales. Job seekers are drawn to organization with diverse workforce because it is evident that the organization do not practice employment discrimination. Potential employees want to know that employers treat their staff fairly regardless of race, ethnicity or gender. Not only are such organizations able to attract new talent but they can also retain existing talent because of high employee morale resulting from diversity.

Diversity plays a significant role in the growth and performance of organization. Organizations that hire employees from diverse countries, cultures, values and styles believe that diverse groups are more likely to possess a broader range of task - relevant knowledge, skills, and different opinions that can benefit each other.

Hubbler (2004), stated that, to understand co-cultural relations, the life experience of those in subordinate position should be explored. When employees are marginalized into groups, it will bring different perspective to an organization that challenges the status quo since their social constructed world view will differ from that of the dominant group (De pree, 2004). Although the standpoint of the dominant group will often carry more weight, a transformational manager needs to encourage conflicting standpoints to co-exist within an organization. Conflicts stem from challenging the way things have always been done, and or ideas and problems that have not been explored from multiple perspectives. Standpoint theory gives a voice to those in position to see patterns for behavior that those immersed in the culture have difficulty acknowledging (Allen \& Branda, 2002).

These unique and varying standpoints help to eradicate group thinking which can develop within a homogeneous group. Scot Page's (2007) mathematical modeling research of team homogeneous teams on a variety of tasks points out that diversity in teamwork is not always simple and that there are many challenges to fostering an inclusive environment in the workplace of diverse thoughts and ideas.

Globalization in this recent time has triggered more interaction amongst people from different cultures and backgrounds than before. People are now more open-minded in the marketplace worldwide with competition coming from almost everywhere in the continent. Diversity can be a problem to an organization but could also be a solution, It also comes with its disadvantages but also benefits and dangerous but also constructive. The challenge then is to extract the very essence of diversity and tactically manage it for the improvement of the people and the organization. Increasing and improving workplace diversity has become an important issue for management in the recent years due to the recognition of how the workplace is changing. Since managing diversity still remains a challenge in organizations, managers tend to learn managerial skills needed in a multicultural 
working environment and prepares themselves to teach others within their organizations to value cultural differences and treat all employees with dignity. For some organizational leaders and managers point of view, diversity is a big challenge to them although it knows no organizational boundary and has no limitations. There are some elements or dimensions of societal diversity in an organization such as education, ethnicity, religion and culture that pose challenges to an organization which will be discuss below

\section{The Elements of Diversity}

For organizations to attract a broader or wider talent pool of employees, it needs to embrace an organizational culture of societal diversity and ethics. This will lead to an enhanced corporate reputation and strengthened cultural values. According to Childs, (2005) diversity is a global workplace and market place phenomenon. Therefore, for an organization to be successful it must have a borderless view and an underlying commitment to ensure that diversity is part of its day-today business conduct. The elements are;

\section{Educational Diversity}

The knowledge acquire from the society by people, contribute to the success of any organization because education is the key that unlocks the forces of economic development. The quality efficiency and structure of industrial organizations are determined by the quality of the people who are there. It is believed that the level of education in a country directly influences the performance of organizations in that country. So, managers need to develop strategy to manage the people with different qualifications in the organization for efficiency and effective performance. Education emphasizes the need to develop a skilled and flexible workforce in order to compete in the twenty first century. Issues which challenge the human resources management are many and these issues are best solved using the educational system. Recent examples from Nigeria educational system have shown that it is the type and depth of knowledge that is paramount in education meant for industrial enterprise. There is no country that can develop technologically without quality education. The quality of education is significantly more important than mere quantity.

Effective education as one of the dimension of diversity, enhances exposure, training and development which promote understanding and congenial acceptance towards the realization of overall goals of the organizations to become more creative, reach previously untapped markets and in general, achieve and maintain a competitive advantage.

In most organizations, educational diversity management is implemented in order to encourage employees to work effectively with others so that organizational objectives can be achieved. An individual educational level can be an indicator of knowledge, skill, and capability (Gwendolyn, 2002). It is right to conclude by saying that educational background in the society is one of the factors that account for the differences in the organizational performance. Once an organization has a poor educational standard and other factors in the organization- structure, organizational culture will be sadly deficient. It is clear that the level of literacy, the type, quantity and quality of education, affect the performance of the functions of the organizational planning, organizing, directing and controlling. 
The treatment of educational investment as investment in human capital rests on the assumption that education acquired by individuals will lead to an increase in their effectiveness. Education is thought to raise effectiveness through the provision of skills and knowledge, which increase the efficiency and hence the value of the more educated.

Neo-classical economic theory stated that, wages are determined on the basis of a worker's marginal contribution to a firm's revenues. Given that earnings reflect differences in effectiveness, the additional earnings of the educated can serve as a measure their contribution to output. Thus, the extra earnings of the educated are a reflection of their higher effectiveness.

Education emphasizes the need to develop a skilled, knowledge in order to be able to face future challenges. Where there are employees with different educational qualifications, the management needs to develop a strategy to manage them properly so that organizational goals can be achieved. Difference in educational background seems to have positive impact on team performance because it fosters a broader range of cognitive skills. Childs (2005) observed that organization's economy can be more productive as the proportion of educated workers increase. Educated worker carry out tasks that require literacy and critical thinking efficiency.

\section{Ethnic Diversity}

There is increase in multicultural diversity in the society as well as the organizations and this is as a result of increase in the population of the society. Ethnic diversity in the society is highly relevant in an increasingly globalized world. Ethnicity means people who identity with each other based on common language, ancestral, social, and cultural. Unlike most other social groups, ethnicity is primarily an inherited status (Ahiauzu, 1999). A moderate level of ethnic diversity has no effect on team performance in terms of organizational outcome that is sales, profit and market share. However, if at least the majority of team members are ethnically diverse, it will have a positive impact on performance (Sander Hoogendoom, Mirjamvan Praag 2012).

There are many ethnicity in the society and it is a source of heterogeneity because, ethnically diverse teams working in relatively homogeneous organizations experienced performance deficits (Joshi \& Jackson, 2003). According to Ostergaard, Christian R \& Timmermcins, Bram \& Kristinsson, Kari (2011) study, ethnicity can be used as a proxy for cultural background and diversity in ethnicity can be expected to be positive for innovative performance, since it broadens the viewpoints and perspective in the firm (Richard, 2000). Moreover, there are some levels of diversity in ethnicity that might be positive which is associated with innovation, ethics behavior, but, high degree of diversity in ethnicity might be negative since it can create conflict and cliques due to social categorization (Dahiln, 2005).

Ehimare \& Oghene (2011) believed that, ethnicity in an organization, is insignificantly negative to effectiveness. But, ethnic diversity benefits team performance due to the fact the more diverse pool of skills and knowledge are acquired. Ethnic diversity is associated with difficulty in communication and coordination, if not properly managed (Vardy, 2009). It has been discovered, teams made up of people from different cultural viewpoints show more creativity and unfamiliar situations. Ethnic 
diversity may be very useful in completing a task that requires many different competencies. There is nothing magic about the performance of a diverse team - it can be better if members of team understand how to make use of their differences to improve performance, but it can also be worse if they do not know how to achieve that improved performance. Based on the literature reviews, it is revealed that when different ethnic groups in the society are properly managed in an organization, the ethnicity diverse workforce will have positive impact on organizational effectiveness.

Management scholars observed that despite high level of managing ethnic diversity in an organization, it leads to conflicts of various kinds, such as nepotism, corruption and stereotyping in the organization and this can leads to inefficiency of the organizational performance. Ehimare \& Oghene (2011) suggested that flat sharing among people of different ethnic backgrounds, encouraging common language among others can go a long way to improve organizational efficiency and effectiveness.

\section{Cultural Diversity}

Actions and ideas that form part of an organization's culture can come from anyone within the organization. It is however, more common place for it to begin from a company founder or from one of the early leaders of the organization. Therefore, culture is the pattern of values, norms, beliefs, attitude and assumptions in the society that may have been articulated but shape the ways in which people in organization behave and things get done. In other words, culture is a unique configuration of norms, beliefs and ways of behaving that characterize the manner in which groups and individuals combine to get things done. The behaviors and actions of top management help to project and sustain the desired type of behavior for all in the organization.

According to Ahiauzu (1999), cultural diversity in the society implies diversity in religion, norms, values and attitude. The growth of societal cultural diversity was the focus since before Christ was born. To achieve organizational goals, the management needs to manage employees with different cultural diversity. When people of the same culture are grouped together to perform a specific task, it will lead to high effectiveness and efficiency of the organizations. Diverse cultural system is an influential source of heterogeneity which can be positive on efficiency and effectiveness. This is as a result of different people pooling their belief, knowledge and skill together to achieve effective productivity in the organization.

\section{Diversity Management}

An integral and essential feature of individual differences in the society, is the concept of diversity. In fact, people are not homogeneous. The various diversity in the society focuses on the multiplicity of differences among people - on the variety of people as heterogeneous grouping. Individual differences in the society are the basis of diversity. Individual differences and diversity have been recognized as important for effective team performance but in recent years greater attention has been given to the management of societal diversity. Therefore, diversity Management can be defined as the process of planning, directing, organizing and applying all the comprehensive managerial attributes for developing an organizational environment, in which all diverse employees irrespective 
of their similarities and differences in the society, can actively and effectively contribute to the competitive advantage of a company or an organization.

However, valuing differences is easier said than done. It means relating and working with people who hold difference perspectives and views, bringing different qualities to the workplace, having different aspirations and having different customs and traditions. Differences are challenging; they question people's views, perceptions and attitudes and require individuals to see things from a different frame of reference. Managing diversity in an organization, does not mean that managers champion their own values and try to shift other people's values to conform and match their own.

According to Kreutzer, (2001:37) diversity "Stands for the various differences in individuals as well as similarities that exist among them." Kreutzer's definition emphasizes on the following crucial issues about diversity management; diversity applies to all employees and do not only encompass certain range of differences but the entire spectrum of individual differences that makes people unique. Therefore diversity cannot be viewed as only racial or religious differentiation, but it is the combination of all differences. The concept of diversity defines differences among people and also their similarities. The act of managing diversity requires that these two aspects be dealt with and managed at the same time. Managers are therefore expected to integrate the collective mixture of similarities and differences between workers into the organization. As such, diversity can be described as having four layers (Kreutzer, 2001:3). Traditionally, the term diversity has been widely used to refer to the demographic composition of a workforce. Some studies have looked at diversity using the compositional approach, otherwise known as Surface-level diversity (SLD) or demographic diversity, which refers to the extent to which a unit is heterogeneous on characteristics such as gender, ethnicity, religion, age, functional background, and organizational tenure.

Diversity Management is the ability of a manager to achieve success for an organization by making the best of use of the similarities and differences among employees in terms of age, cultural background, physical abilities and disabilities, race, ethnicity, religion, sex, as well as in terms of personality, values, attitudes, perception and cognitive style. Individuals who think towards deep level diversity are more likely to perceive themselves as similar, rather than dissimilar, to members of their workgroup on unobservable qualities. Workforce diversity refers to a workforce made up of people with different human qualities or who belong to various cultural groups. The author regarded individual diversity to include people different from themselves along the dimensions such as social background. Diversity management is about finding ways to get the diverse contributions from employees. It may seem that the dynamics of diversity are especially salient in teams. This may be because it has been observed that where the level of face-to-face interaction is high, members often rely on one another to perform their tasks effectively (Tsui and Gutek, 2000). Indeed, empirical research in organizational and laboratory settings suggests that diversity make a difference for group outcomes and significantly affect the experiences of the individuals within the team (Harrison et.al, 2002; Jackson, et.al, 2003).

However, Diversity management issues abound in organizations and it is expedient that they are proactively identified and appropriately addressed. Prejudice and discrimination seem to be alive 
more in settings where there are diverse sets of persons. The contemporary Nigerian workplace may be a typical example. Managing diversity in an organization is the planning and implementing organizational systems and practice that will favor the organization. For organization to survive, the company needs to manage and utilize its equality principle. Once these policies are in place, the company can begin implementing diversity measures throughout the entire organization. When hiring employees, qualification should be based on the quality of his experience, not age or any other category. When diverse qualified workforce are hired, the manager will be able manage the diversity in the organization. The skills of qualified employees need to be utilized and favoritism and discrimination should be discouraged among the employees.

One of the goals of every organization is to hold quarterly training for the entire staff concerning diversity in the workplace and encourage them to discuss issue that concerns how the organization can better manage workplace diversity.

According to some management scholars, policy on managing diversity recognizes that there are differences among employees and that these difference, if properly managed, will enable work to be done more efficiently and effectively. It does not focus exclusively on issues of discrimination but instead concentrates on recognizing the differences between people.

Randola and Fullerton (1994) believed that, managing diversity is founded on the premise that harnessing these differences which will create a productive environment in which everyone will feel valued and their talents will be fully utilized. For organizational performance to be effective and efficient, it depends on the ability of human resource management to manage societal diversity in an organization. Managing diversity is a concept that recognizes the benefits to be gained from differences.

A management of diversity policy should;

$>$ Acknowledge culture and individual differences in the workplace;

$>$ Value the different qualities that people bring to their jobs.

$>$ Eliminate all kind of bias in area of selection, promotion, performance assessment, pay and learning opportunities.

$>$ Give attention on individual differences rather than group differences.

According to Oparanma, (2008), the top management needs to provide strong leadership, that is, good combination strategy. The top management needs to show commitment and support to the subordinates in the organization when managing diversity. Surveys method need to be used to measure current employees' attitude and perceptions of diversity and relationship within the groups.

Educating the people is achieved by providing diversity training and also creating awareness training that can promote effectiveness and efficiency in the organizations which can also promote better ethical behavior both in the society and in an organization. 


\section{Concept of Ethics}

Ethics is a moral belief that influences people's behavior, attitudes, and ideas in the society. Ethics is the rule and principles that defines right and wrong conducts (Robbins \& Coulter, 1999). To know right from wrong and to know when you are practicing one instead of the other determines a manager's ethical intelligence. Erondu et al (2004) hold that the study of ethics focuses on issues of practical decision-making, including the nature of ultimate value, and standards by which a human action can be judged right or wrong, good or bad. Ethics is the application of ethical values, such as fairness, openness, integrity, to all organizational behavior. In other words, ethics is the study of moral obligation, or separating right from wrong. In short it is about how an organization does its business. Does it treat its employees with dignity and respect? Does it support them to do the right thing? Does it treat its customer fairly? Does it pay its suppliers on-time? Is it open to dialogue with its local communities? Does it acknowledge its responsibilities to wider society? Societal ethics are moral principles that guide the way an organization behaves. The same principles that determine an individual's actions also apply to organization. Societal and organizational ethics are often guided by law, while other times provide a basic framework that businesses may choose to follow in order to gain public acceptance.

Organizational ethics is a form of the art of applied ethics that examines ethical rules and principles within a commercial context, the various moral or ethical problems that can arise. Understanding and practicing good organizational ethics is an important part of a manager's job. One of the many reasons ethics are important is that customers and suppliers prefer to deal with ethical organizations.

Unethical behavior of an organization can led to bad image. According to Ogbechie, (2016), a lot of efforts have been made to curb unethical behaviors and indiscipline in organizations and the society by different leaders in Nigeria but their efforts have, significantly, not yielded tangible results. So, organization need to create an ethical workplace and put organizational codes of conduct in writing for the employees to follow. For management to foster ethical behavior in an organization, the management needs to put the following approaches into consideration.

\section{a. Cause and effects approach.}

People working in organizational setting should keep their conduct as the main cause which will result in effecting the best interests of society at large.

b. Fundamental rights approach.

This approach suggests that the fundamental rights of people should be protected.

There should be no exploitation on people and there should be no violation of human rights.

\section{c. Organizational justice approach.}

Organizational justice and fairness to people in organizations, can be classified into four categories; such as;

a. Distributive Justice. This is refer to fairness of rewards e.g., compensation received. This leads to their satisfaction.

b. Procedural Justice which is regarded as the fairness of the procedures used to determine the outcomes they receive. People tend to follow organizational rules and policies when they are satisfied with the procedures. 
c. Interpersonal Justice. This means fairness of interpersonal treatment. This leads to the fulfilment of affiliation needs.

d. Informational Justice. This is refer to the fairness of the information used as the basis for making decision. People tend to be confident when they have a right to information.

According to Kant, (1953) a person's action is ethical only if that person is willing for that same action to be taken by everyone who is in a similar situation. This is same as the Golden Rule - Treat others as you would like them to treat you. For example, padding an expense account would be considered ethical, if the person were also willing for everyone to do the same if he or she were the boss. Because it is very doubtful that considered unethical. A person should never treat another human being simply as a means to an end but always as an end in itself. This means that an action is morally wrong for a person if that person deals with others just as means of advancing his or her own self interests. To be moral, the act should not restrict another people's actions so that they are left in a position of disadvantage. Good ethical behavior in the society can be of a benefit to the organization in a long run.

The relevance of ethics to this present study is that people of different background value fair treatment which enable them to be motivated to keep the trust maintained within the relationship of their co-workers and the organization. If an employee feels that his/her input are rewarded fairly by outputs, then he/she will be happy with his/her work and employer hence, will be motivated to continue putting more inputs and avoid unethical behavior knowing that he will be rewarded appropriately. If the employee feels that his/her input to outputs is less compared to the output enjoyed by others in similar situation within the organization, the employee will not be happy with the employer and the organization at large. This disparity can lead to workplace unethical behavior such as open hostility, reduced effort at work, absenteeism, sabotaging organizations equipment. Therefore, equity in the workplace promotes trust, ethical behavior and also reduces workplace unethical behaviors.

\section{Benefits Derived from Ethical behavior in an organization.}

Ethical behavior act is not always free. Organization being ethical in practice by telling customers the absolute truth about product problems, granting social leaves of absence may not have an immediate return on investment. Nevertheless, evidence has shown that high ethics is related to good financial performance.

Ethical behavior in an organization promote efficiency and effectiveness. Unethical behavior has a negative impact on the stock price for an appreciable period of time. Unethical behavior, therefore, reduces a firm's wealth. Being ethical helps to avoid the costs of paying huge fines for being unethical. So many organizations have been fined for unethical and illegal activities. For example, Texaco Corporation paid fine of $\$ 180$ million for discriminating against people for color.

The relationship between profits and social responsibility works two ways in another perspective. More profitable organizations can better afford to invest in social responsibility. Economic and legal 
responsibilities coexist in an organization because they represent the minimum threshold of socially expected business behavior. Ethics are the rules of moral values that guide decision making by groups and individuals. They are a person's fundamental orientation towards life - what he or she sees as right and wrong. Ethical responsibilities of an organization encompass how the organization's decisions and actions show concern for what its stakeholders (employees, customers, stockholders and the community) consider fair and just. Ethical behavior involves knowing what is right and wrong, and behaving accordingly. Behaving ethically can contribute success to the society and the organization.

Legality may be considered as the first ethical standard. Some people wonder if being ethical these days simply means not getting caught doing something illegal. The only question seems to have become 'Is it legal? A society gets into trouble when it considers ethics and legality to be the same. Ethics are legality are two different things. Although following the law is an important first step, ethical behavior requires more people treat others? What responsibility should they feel for others? Legality is more limited. It refers to laws we have written to protect ourselves from fraud, theft and violence. Many immoral and unethical acts fall within our laws.

Virtually all cultures agree that basic moral values like integrity, respect for human life, self-control, courage and self-sacrifice are right; cheating, cowardice and cruelty are wrong. All of the world's major religions support a version of the Golden Rule, even if it's only in the negative form; do not do unto others as you would not have them do unto you.

It is always healthy when looking at moral and ethical issues to remind ourselves that ethical behavior begins with you and me in the society. We cannot expect society to become more moral and ethical unless we as individuals commit to becoming more moral and ethical ourselves. It is therefore important to always keep ethics in mind whenever you are making a business decision. The choices are not always easy. Sometimes the obvious solution from an ethical point of view has drawbacks from a personal or professional point of view. For example, imagine that your supervisor has asked you to do something unethical. Meanwhile, you have only recently secured a loan to buy a house in anticipation of your first child due in two months. Not carrying out your supervisor's request may get you fired. What would you do? Sometimes, there is no desirable alternative. Such situations are called ethical dilemmas because you must choose between equally unsatisfactory alternatives. It can be very difficult to maintain a balance between ethics and other factors such as pleasing stakeholders or advancing in your career.

It is helpful to ask the following questions when faced with an ethical dilemma:

a. Is it legal? - am I violating any law or organizational policy? Whether you are gathering marketing intelligence, designing a product, hiring or firing employees, planning on how to get rid of waste, etc., it is necessary to think about the legal implications of what you do. This question is the most basic one in behaving ethically in organization, but it is only the first.

b. Is it balanced? - am I acting fairly? Would I like want to b treated this way? Will I win everything at the expense of another party? Win-lose situations always end up as lose-lose 
situations. There is nothing like a major loss to generate retaliation from the loser. Within an organization, imbalance can eventually lead you to use your limited resources to combat the competition in the "back room" rather to compete in the marketplace. Not every situation can be completely balanced, but it is important to the health of relationships that we avoid major imbalances over time. An ethical organization person has a win-win attitude. In other words, such a person tries to make decisions that benefit all parties involved.

c. How will it make me feel about myself? Would I feel proud if my family learned of my decision? Would I be able discuss the proposed situation with my immediate supervisor? The company's clients? How would I feel if my decision was announced on the evening news? Would I have to hide my actions or keep them secret? Has someone warned me not to disclose my actions? Am I feeling unusually nervous? Decisions that go against our sense of right and wrong make us feel bad - they erode our self-esteem. That is why am ethical business person does what is proper as well as what is profitable to the society and the organization.

Ethical dilemmas can be magnified by differences in language, culture and organizational practices. Organization should manage ethically for the following reasons; to maintain a good reputation, to keep existing customers, to attract new customers, to avoid lawsuits, to reduce employee turnover to avoid government intervention, to please customers, employees and society, simply to do the right thing etc.

Philanthropic is the highest level illustrated on the social responsibility pyramid. It includes organizations participating in programs that improve the quality of life, raise the standard of living, and promote goodwill. The difference between ethical responsibility and philanthropic goodwill is that the latter is seen not so much as an obligation but rather as a contribution to society to make it a better place. Organization that do not participate in these activities are not seen as unethical, but those that do tend to be seen in a more positive light. Philanthropic goodwill may be described as the level of social responsibility in which an organization does well without the expectation of anything in return. It should be noted that philanthropic activity is not limited to the wealthy or to large corporations but average citizens of small organization can be and are philanthropic.

\section{Ethical Values in Organization}

Ethical concerns are an important area in business practices and research endeavors in the field of management. In particular, ethical concerns become evident in situations of a symmetric relationships across organizations. The need of the hour is to establish ethical codes, processes and performance measures in today's corporate houses. In a prior research restricted parts of this idea across the organizations have been addressed from an ethical perspective but not the whole process (Moberg, 2003; Geraint, 2003; Kidd, 2003; Carter, 2000; Cooper et. al, 1997; Stainer, 1997). Nevertheless, there have been a few recent research that is dedicated to the ethical concerns in organizations as a whole. For example, Svensson \& Baath, (2008) introduced and described a conceptual framework of organizational ethics based upon the automotive industry. 
Svensson, (2009) focuses on the transparency of organization to manage ethics based upon case illustrations across organizations in the fashion and telecom industries. The dilemma is that these ethical frameworks in this field are still nascent stage, where specific details are not provided on how to manage, monitor and evaluate ethical concerns across organizations. In fact there are multiple research topics that might be linked implicitly or explicitly to ethical concerns in across organizations, such as: chain management ethics (Svensson \& Baath, 2008; Svensson, 2009), corporate social responsibility (Dyllick \& Hockerts, 2002), environmental marketing (Sheth \& Parvatiyar, 1995), environmental marketing management (Peattie, 1995) and environmental product differentiation (Reinhardt, 1999), environmental management (Hoffman, 2000). There are various areas of ethical concerns across organizations. On an overall level there are both external and internal areas. Robin \& Reidenbach, (1987) developed a multidimensional scale for improving evaluations on business ethics, while Hunt et. al, (1989) developed a corporate ethics scale. On the one hand, business ethics has an external emphasis considering the gap between organizations' ethical actions and behavior in ongoing business practices and the marketplace's or society's perceptions of the organization's ethical actions and behavior in their business practices (Svensson and Wood, 2004). Corporate ethics, on the other hand, has an internal emphasis considering the gap between the management's ethical actions, behavior and the staff's perception in ongoing business practices (Svensson and Wood, 2004).

It is not an easy task to determine what may be classified as ethical or unethical business practices across organizations as a whole. An essential factor is that there are expectations and perceptions that vary between organizations. These expectations and perceptions also vary in the marketplace and societies that surround organizations, and that influence the predominant belief or conviction of what may, or may not, be seen as ethical business practices. There are several areas that contribute to this variable situation. For example, government legislation may frame and define the criteria of ethical business practices across organizations. Developed western style democracies have laws that govern the expected and perceived actions and behaviors in business practices as they tend not to be self-regulatory (Carson, 2003; Davies, 2001; Piety, 2004; Rondinelli, 2003).

Historically, they have been able to impact societies' and their citizenry's expectations and perceptions of organizations' business practices (Grit, 2004; Whawell, 1998). Organizations are also confronted with societal expectations and perceptions beyond purely economic issues, such as environmental and social change responsibilities (Handelman, 2000; Handelman \& Arnold, 1999). With the awakening of globalization has come a realization in first world economies that there are organizations who appear to have diverse sets of actions and behavioral standards depending upon the country in which they find themselves at the time (McMurtry, 2002; Sorensen, 2002).

The desire to build trusting internal and external relationships, as well as growing pressures from wider society, should lead the owner and manager of an organization to consider to what extent ethical values and principles guide their organizational behavior. What does 'doing the right thing' mean? Organizations are characterized by informal understandings and shared expectations among the workforce of how business is done. Any values and ethical principles will usually be implicit 
rather than formally expressed through ethics policies, codes and programs that are familiar in large organizations. The ethics of a small organization is typically influenced by the society, owner manager or managing director. Through their very visible presence, their personal attitudes and behaviors will set the tone of the business and have the potential to signal to employees how seriously ethical behavior is to be taken in the organization. Some small organizations are not typically able to devote as many resources to building an ethical workplace culture as larger organizations. However, there are advantages to having a somewhat more formal ethics policy in place. First, it reinforces and makes explicit the values and principles that are part of the organizational culture, so allowing them to be communicated to stakeholders. Second, a policy will provide guidance and support to employees on how they are expected to conduct their organization. A policy will provide a context and the vocabulary for employees to raise any concerns they have with their supervisors or the directors. It will form a framework for management and staff to decide what the right thing to do is.

\section{Ethics and Organization Strategy}

Organization ethics which originated from the society, means more than simply passing moral judgment about what should and should not be done in a particular situation. It is part of the conscious decisions you make about the directions you want your organization to take. It is a like between morality, responsibility and decision making within the organization.

In 1998, BusinessWeek published a poll taken by asking those operating small and large organizations or businesses whether they found certain business practices to be acceptable or unacceptable. The poll found the following questionable practices completely unacceptable, either as an entrepreneur, small organization or business owner or big organization. Such as; use of company services for personal use, removing company supply for personal use, overstating expense accounts by more than $10 \%$, overstating expense accounts by less than $10 \%$, using company time for non-company purposes taking extra personal time, authorizing subordinates to violate company policy, falsifying reports, hiring rival's employees to learn trade secrets and taking longer than necessary to do a job.

A code of ethics is a formal statement explicitly or implied of what the organization expects in the way of ethical behavior. It can serve as a guide for employee conduct to help employees determine what behaviors are acceptable. Because the purpose of a code of ethics is to let everyone know what is expected and what is considered right, it should be included in an employee handbook.

The code of ethics should reflect the employee ethical ideals, be concise so that it can be easily remembered, be written clearly, and apply equally to all employees, regardless of level of authority. The expectations and the consequences of breaking the code should be communicated to all the employees. Small organizations, especially in fast-paced, high-tech industries, often ignore formal codes of conduct because of their push for rapid growth. This mistake can cause expensive legal problems later. An explicit code of ethics and the expectation that employees must adhere to it can reap many benefits for organization, which include the following; obtaining high standards of performance at all levels of workforce, reducing anxiety and confusion over what is considered acceptable employee conduct, allowing employees to operate as freely as possible within a defined 
range of behavior, avoiding double standards that undermine employees' morale and productivity and developing a public presence and image that are consistent with organization's ideals.

To maintain and encourage ethical behavior in an organization, it must be part of the company's goals. By establishing ethical policies, rules and standards in code of ethics, can be treated like any other company goal, such as increasing profit or market share. Establishing ethical goals allows organization to take corrective action by punishing employees who do not comply with company standards and by rewarding those who do. If the organizational ethics is supported and strictly enforced by employees' management team, it will become part of the company's culture and will improve ethical behavior. Conversely, if the managers and employees see the code of ethics as a window-dressing façade (i.e. deceptive outward appearance), it will accomplish nothing. Don't just take a three "Ps" approach - print it, post it, and pray they read it. Instead, talk about the code when it is implemented, review it annually, and use employee suggestions to improve it.

\section{Making Decisions about Ethical Issues Organizations}

Although there are various societal ethical issues that may arise in an organization, it can be difficult to recognize specific ethical issue in practice. Whether a decision maker recognizes an issue as an ethical one often depends on the issue itself. Managers, for example, trend to be more concerned about issues that affect those close to them, as well as issues that have immediate rather than longterm consequences. Thus, the perceived importance of an ethical issue substantially affects choices, and only a few issues receive scrutiny, while most receive no attention at all.

Open discussion of ethical issues in the society does not eliminate ethical problems, but it does promote both trust and learning in an organization. When people feel that they cannot discuss what they are doing with their coworkers or superior, there is a good chance that an ethical issue exists. Once a person has recognized an ethical issue and can openly discuss it with others, he or she has begun the process of resolving an ethical issue. Companies subcontracting manufacturing operations abroad are not aware of the ethical issues associated with supporting facilities that abuse and/or underpay their workforces. New codes of conduct have been established to assist companies in identifying and addressing these ethical issues.

Ethical decisions involve questions about how we ought to behave. The decision process must consider cultural and religious background. A review of the literature will reveal many possible frameworks for making ethical and moral decisions, but all will consider the matter relative to that standard held important by the decision maker. Such traits as honesty, compassion, and fairness, as well as the individual's sense of right and wrong, will play an important part.

For organization to improving the ethical behavior, the management needs to understanding how people make ethical choices and what prompts a person to act unethically may reverse the current trend toward unethical behavior in an organization. Ethical decision in an organization is influenced by three key factors: individual moral standards, the influence of managers and coworkers, and the opportunity to engage in misconduct. While you have great control over your personal ethics outside 
the workplace, your coworkers and management team exert significant control over your choices at work through authority and example. In fact, the activities and examples set by coworkers, along with rules and policies established by the organization, are critical in gaining consistent ethical compliance in an organization. If the company fails to provide good examples and directions for appropriate conduct, confusion and conflict will develop and result in the opportunity for misconduct. If your boss or coworkers leave work early, you may be tempted to do so as well. If you see coworkers making personal long-distance phone calls at work and charging them to the organization, then you may be more likely to do so also. In addition, having sound personal values contributes to an ethical workplace.

It is difficult for employees to determine what conduct is acceptable within an organization if the firm does not have ethics policies and standards. And without such policies and standards, employees may base decisions on how their peers and superiors behave. Professional codes of ethics are formalized rules and standards that describe what a company expects of its employees.

Codes of ethics, policies on ethics, and ethics training programs advance ethical behavior because they prescribe which activities are acceptable and which are not, and they the opportunity for misconduct by providing punishments for violations of the rules and standards. The enforcement of such codes and policies through rewards and punishments increases the acceptance of ethical standard by employees.

Enforcement of ethics policies is a common way of dealing with ethical problems. A survey by the US Ethics Resource Center on attitudes toward and knowledge of ethics and ethics programs indicated that employees' personal ethics improve when their organization has a comprehensive ethics training program. In addition, the study found that individuals in companies that have ethics training programs believe that their business ethics have improved during the course of their careers. These findings suggest that people do bring a set of personal values into an organization, and further, that organizational pressures affect not only how individuals conduct themselves within the organization but also can improve their personal ethics outside of work.

The Conference Board of Canada points out that having a ethics program is not only part of being a socially responsible corporation but is also likely to increase profitability. Lost sales, legal fees, and fines, and the demoralization of the workforce resulting from unethical behavior can be very costly. In an effort to avoid such costs, many Canadian organizations are implementing ethics programs to ensure that employee behavior is in accordance with corporate values and relevant legislation.

Because ethical issues often emerge from conflict, it is useful to examine the causes of ethical conflict. Business managers and employees often experience some tension between their own ethical beliefs and their obligations to the organizations in which they work.

Many employees utilize different ethical standards at work than they do at home. This conflict increases when employees feel that their company is encouraging unethical conduct or exerting pressure on them to engage in it. 
Individuals also play a key role in promoting ethical decisions in the workplace. Whistle blowing occurs when an employee exposes an employer's wrong doing to outsiders, such as the media or government regulatory agencies. However, more companies are establishing programs to encourage employees to report illegal or unethical practices internally so that they can take steps to remedy problems before they result in legal action or generate negative publicity. Unfortunately, whistle blowers are often treated negatively in organizations. Recent business failures, including Enron, have focused renewal attention on whistle blowing. Companies, US companies in particular, have adopted a sophisticated array of options to facilitate whistle blowing including 24-hour hotlines and corporate ethics officers.

A recent survey carried out by the Public Service Alliance of Canada indicates that 89 percent of Canadian wants the government to bring in legislation so that public sector workers who expose government wrong doing would be protected against any reprisals.

The current trend is to move away from legally based ethical initiatives in organizations to culture or integrity-based initiatives that make ethics a part of core organizational values. Organizations recognize that effective business ethics programs are good for organizational performance. Organizations that develop higher levels of trust function more efficiently and effectively and avoid damaged company reputation and product images. Organizational ethics initiatives have been supportive of many positive and diverse organizational objectives, such as profitability, hiring, employee satisfaction, and customer loyalty.

\section{Ethical Issues in Diversity Management}

Gender, culture, education, ethnicity and religion were studied as surface level dimensions of diversity management while deep level diversity management dimension was looked at in terms of individual's locus of control and the perception of the equity level in the organization. This was done by the measurement of organizational performance which was looked at in terms of its productivity, profitability, effectiveness and efficiency, rate of employee turnover and innovativeness. It has been observed that group difference and histories are accentuated as "us" versus "them" tension often increases infighting that interferes with progress.

Nigeria is easily described as a multi-lingual and multi-ethnic nation. Otite (2000) provides a tentative figure of more than 389 ethnic groups. Organizations where an ethnic group seems to be in the majority, there may be other differences which vary along such subgroups dimensions as dialect, village, clan and kin group all of which tend to create tension. As far as tension often increases infighting, the organizations' productivity will likely be affected negatively. A firm's degree of innovativeness is crucial for its sustainability and growth. It has been observed that women with high self-efficacy and internal locus of control scored higher on entrepreneurial innovative behavior than women with low self-efficacy and external locus of control.

However, when employees sense that being a member of a group appear to be instrumental to gaining organizational favors, there may be a loss of confidence in his ability to attain preferred heights in the organization, whether he or she has an internal locus of control or not. The greater the 
INTERNATIONAL JOURNAL OF ACADEMIC RESEARCH IN BUSINESS AND SOCIAL SCIENCES

Vol. 9, No. 2, Feb, 2019, E-ISSN: 2222-6990 C 2019 HRMARS

extents to which employees are disturbed by issues of their diversity the more negative the effect on Corporate Performance.

The role of ethics in management is also dependent on the level of responsibility. The organization is willing to take. The pro-active mode would characterize a company that believes strongly in its mission as moral (or at least for the benefit of society). It would respond as a trend setter to some of the ethical dilemmas (Clief, 2009). The re-active mode would be the companies though aware of social responsibility, respond to immediate situations rather than anticipating them. The passive mode leads the company to deviant behavior by refusing responsibility (Satus, 2003). There are two main extremes found in the corporate world, profit on one side and human safety, which constitute an ethnical spectrum.

The main goal of management ethics is to treat all employees and customers justly and fairly. It is believed that by following a moral and ethical code, organization will improve. When management team adheres to management ethics, employees will become motivated and the workplace environment will become motivational. When applied to everyday business, acting ethically means adhering to law, competing with others in an honest manner, and performing daily tasks without any element of deceit. Many organizations around the globe update written codes of conduct as a result of past corporate scandals. It is not uncommon for a company to update this document on a yearly basis. After a code of conduct document has been up0dated, each staff member must read and understand the document (Nathan, 2001). Further, all employees must adhere to the updated codes of conduct, and those that do not follow these regulations are often dismissed. Although managers must follow the same codes of conduct as employees, these individuals have additional obligations. Almost every decision that is made on a daily basis involves an ethical decision. Managers must keep this in mind at all times. By setting a good ethical example for other employees, managers can easily encourage all employees to follow the same ethics. Some organizations offer managers specialized management ethics courses that must be completed prior to job acceptance. Frequently, managers who switch companies are asked to follow a different code of conduct. This does not mean that all other management ethics should be forgotten, but it does mean that additional ethics should be learned. Ethics are not necessarily interchangeable from country to country. Sometimes, different cultures respect different ethical rules. Thus, any person who decides to move to another country may have to adapt to cultural, and workplace, ethical differences.

The purpose of Diversity Management is to tap into the positive potential of diversity and transform this potential into a reality. Organizations are reassessing their structures and processes in the light of equal opportunity (Paulson, 2011). Awareness of diversity, ethics and competence in its management are necessary prerequisites for success. Many business and other organizations have already developed diversity management programs with some success. Having originated in the US in the early 1980s, diversity management is to some extent already established in many organizations (George, 2009). 
In Nigeria, there seems to be movement away from equal opportunity, which often, albeit sometimes unintentionally, leads to quotas and presupposes assimilation as the main adaptation principle, toward a more systematic, positive, organizational approach of diversity management, towards appreciation of diversity and the conscious striving toward a scientific as well as ethical and resultsoriented approach (Ugoji, 2003). This approach, however, is not easy to put into practice. Conflicts and social issues obviously cannot be overlooked as they are embedded in their complexity and contexts. This complexity entails the fine tuning and nimble use of different tools for dealing with it, and for describing and assessing each unique diversity constellation of any particular organization, community, region or country. For example, in Nigeria diversity takes on a different form than other countries. The different historical and social roots of the Nigerian and other country diversities have to be deeply respected and taken seriously (Friday, 2007). There are no simple recipes. As a consequence, in spite of difficulties in overcoming complexity, diversity management has to assume that people are able and willing to change themselves and their thinking, and thereby define and redefine diversity in a positive light. How can such changes be initiated? What are the political implications? Again, we have not got easy answers but there is one important point we would like to keep in mind. Complex systems often react counter intuitively to the attempts at managing or controlling them. To some extent this was the case of "affirmative action" which has consciously been considered very political (Adewale, 2006).

\section{Conclusion}

Diversity management is a strategy to promote the perception, acknowledgement and implementation of diversity in organizations and institutions. Diversity management is based on the idea that diversity opens up alternative ways of perceiving, thinking and acting and thus enriches the life of an organization or any establishment. Human beings differ in age, social and national background, gender, sexual orientation, physical and mental ability as well as religious belief and worldview. Diversity is a source of creativity and innovation that can provide the potential for future development and competitive advantage. Ensuring that diversity and ethics behavior in an organization is made visible and fruitful remains a central concern of diversity management. In doing so, individual and structural representation of perception and appreciation may be reflected upon. Managers have to perform many roles in an organization and how they handle various situations will depend on their style of management. A management style is an overall method of leadership used by a manager. However, there is no particularly accepted style of management, but styles that lead to increased staff motivation, job satisfaction, ethical behavior and productivity should be encouraged. While those that have the opposite effect should be discouraged. Managers in most organizations commonly strive to encourage ethical practices not only to ensure moral conduct but also to gain whatever business advantage there may be in having potential consumers and employees regard the company as ethical. Creating, distributing, and continually improving a company's code of ethics is one usual step managers can take to establish an ethical workplace and in doing so the mind set of administrators change to accept innovations.

Organizations hire employees from diverse ethnic groups, cultures, values styles. While employees expect returns from the organization, their effective performance is significant for its success. 
Diversity could present tremendous challenges as well as opportunities to the organization in terms of effective management. Sometimes, diversity is connected with adequacy and sometimes it is viewed as negative to organizational performance and frequently it has insignificant impact. Anyhow, the result of this study provides guidelines for the management of diversity and ethics, and suggests that organization managers should be willing to see and locate an immediate positive association between workforce heterogeneity and organizational effectiveness. As an option, impacts are required to be controlled by the procedures that firm takes after and by how different members and association pioneers deal with the diversity in a productive approach to upgrade representative and hierarchical execution. Subsequently, joint examination endeavors to decide the unforeseen variables that can mild workforce diversity to create positive results. This necessity to see completely the many-sided quality of the diversity wonder and the vast volume of information included in its examination while directing a top to bottom study in various business ventures.

Management needs to enhance organizational efficiency by making sure that working environment is conducive for the employees to perform the tasks they have been assigned. Employees with the same cultural system when grouped together to execute a particular task can lead to efficiency. This is as a result of better understanding and cooperation among the employees. Other management scholars believed that efficiency is the time it takes to do something.

Several researchers suggest that, diversity has positive and negative effect, depends on different aspect of the organization's strategies, culture and human resource management practices. This indicates that diversity and ethics behavior may be beneficial under certain conditions and may fail to have any impact on others Pugh (2008). The following factors know to affect the effectiveness of workforce diversity; the size of organization, age of organization and type of organization and diversity of community surrounding the organization can affect an organization.

\section{Recommendations}

Based on the findings in this research, the following recommendations are made:

1. It is recommended that organization need to embrace diversity and ethics management strategies so that organizational performance as well as employees' performance can be achieved.

2. Diversity and ethics should be encouraged, but proper mechanism should be put in place so that the issue of ethnic or cultural division does not become a strong force in the workplace. People should practice their culture at home not at the place of work. The leaders of the organization should live by example and open confrontation about ethical deviations should be encourage.

3. Human resource should formulate strategies to eliminate negative ethnic discrimination climate within the organization. Awareness based training programs should be organized to help employees to reflect on their stereotypes.

4. Human resource management needs to formulate policies that encourage employees' development, or recruitment of employees with diverse educational backgrounds, this will 
INTERNATIONAL JOURNAL OF ACADEMIC RESEARCH IN BUSINESS AND SOCIAL SCIENCES

Vol. 9, No. 2, Feb, 2019, E-ISSN: 2222-6990 C 2019 HRMARS

create a wide pool of knowledge within the organization, thus enhancing organizational ethics and competitiveness

\section{REFERENCES}

Adams, B.D., Thomson, M.H., Brown, A., Sartori, J.A., Taylor, T., \& Wadherr, S. (2008). Organizational Trust in the Canadian Forces. Toronto: Human System.

Adewale, E. (2006). The Strategic Management of Workplace Diversity Issues: Public Sector Implications: International Journal of Public Administration, 13(3), 425-447

Ahiauzu, A.I. (1999). The African Industrial Man. Port Harcourt: CIMRAT Publication.

Carrel, M.R. (2006). Defining workforce Diversity Programs and Practices in Organizations: Longitudinal study. Labor Law Journal, spring

Carson, T.L. (2003). Self-interest and business ethics: some lessons of the recent corporate scandals. Journal of Business Ethics, (43), 389-394.

Carter, C.R. (2000). Ethical issues in international buyer-supplier relationships: a dyadic Examination. Journal of Operations Management, 18(2), 191-209.

Cooper, R.W., Frank, G.L. \& Kemp, R.A. (1997). Ethical issues, helps and challenges: perceptions of members of the Chartered Institute of Purchasing and Supply. European Journal of Purchasing \& Supply Management, 3(4), 189-198.

Dahim, M. (2003). The development of a needs analysis. Instrument for cultural diversity Training: WDQ - 11: Unpublished Manuscript, University of Houston, Texas.

Davies, H. (2001). Ethics in regulation. Business Ethics. European Review, 10(4), 280

De Paula, F.C. (1967). Balance Sheet Fiction Management Today March.

Depree, M. (1998). Leadership is an art. New York

Dietz, J. \& Peterson, L. E. (2006). Diversity Management. Handbook of Research in International Human Resources Management. Edward Elgar Publishing Limited. UK.

Drucker, P (1951). Technology, Management and Society. London: Heinemann.

Dyllick, T. \& Hockerts, K. (2002). Beyond the business case for corporate social . Journal of Operations Management, 18(2), 191-209.

Ehimare \& Oghene (2011). Effect of Ethnic Diversity. UNIBEN. Benin. Nigeria.

Erondu, E.A., Sharlaand, A. \& Okpara, J.O. (2004). Corporate ethics in Nigeria: A test of the concept of an ethical climate. Journal of Business Ethics, 51(4), 349-357.

Geraint, J. (2003). Supply chains: hardest area to score on ethics. Supply Management, 8(7), 1115.

Grit, K. (2004). Corporate citizenship: how to strengthen the social responsibility of managers. Journal of Business Ethics, 53,97-106

Handelman, J. (2000). How marketers can do well while doing good': the institutional theory framework", in Spotts, H.E. \& Meadow, H.L. (Eds), Developments in Marketing Science, 23.

Handelman, J.M. \& Arnold, S.J. (1999), "The role of marketing actions with a social dimension: appeals to the institutional environment", Journal of Marketing, 63, 33-48.

Hoffman, A.J. (2000), Competitive Environmental Management: A Guide to the Changing Business Landscape, Island Press, Washington, DC 
INTERNATIONAL JOURNAL OF ACADEMIC RESEARCH IN BUSINESS AND SOCIAL SCIENCES

Vol. 9, No. 2, Feb, 2019, E-ISSN: 2222-6990 C 2019 HRMARS

Hofstede, G. (1978). Culture and Organization, A Literature Review study. Journal of Enterprise Management.

Hofstede, G. (1980). Motivation, leadership and organization: Do American Theories Apply Abroad.

Hunt, S.D., Van Wood, R. \& Chonko, L.B. (1989). Corporate ethical values and organizational commitment in marketing. The Journal of Marketing, 53, 260268.

Jackson, S. E, May, E.E.E., \& Whitney, K. (2003). Understanding the dynamics of diversity in making teams.

Jain, H. C. \& Vardy, A. (1996). Workforce diversity, employment equity/affirmative action Programs and public policy in selected countries. International Journal of Manpower

Johnnie, P.B. (1988a). Corporate Performance of Public Enterprises in Developing Countries: The Human Factors as a Neglected Area. Journal of African Administrative Studies, 31

Kant, I. (1953). The Groundwork of Metaphysic of morals. New York

Kidd, J. (2003). Learning and trust in supply chain management: disintermediation, ethics and cultural pressures in brief dynamic alliances. International Journal of Logistics: Research \& Applications, 6(4), 259-76

Kreitner, R. \& Kinicki, A. (2001). Organizational behavior, $5^{\text {th }}$ edn. Sydney: McGraw-Hill.

Kreitner, R. \& Kinicki, A. (2004). Organizational behavior, $6^{\text {th }}$ edn. Sydney: McGraw-Hill.

Maslow, R. \& Engel, P. (1973). Productivity strategies, Englewood Cliffs, New Jersey: Prentice-Hall.

Mayo, E. (1945). The social problem of industrial civilization. Boston: Harvard University Graduate School.

McGregor, D. (1960). The Human side of Enterprise. New York: McGraw-Hill

McMurtry, J. (2002). Why the protestors are against corporate globalization. Journal of Business Ethics, 40, 201-215.

Moberg, C.R. (2003). Evaluating the relationship between questionable business practices and the strength of supply chain relationships. Journal of Business Logistics, 24(2), 1-19.

Ogbechie, R. (2016). Business ethics and the challenges of compliance in Nigeria. The International Journal of Business \& Management, 4(12), 192-201.

Oparanma, A. O. (2008). Essential of Business and Management. Port Harcourt. Nigeria

Oparanma, A. O. (2015). M. Sc Lecture Note on Diversity. Faculty of Management Science. Rivers State University. Port Harcourt. Nigeria.

Ostergaad, C. R. \& Timmermans, B. \& Kristinsson, K. (2011). Does a different View create something new? The effect of employee diversity on innovation. Research Policy, Elsevier, 40(3), $500-$ 509.

Peattie, K. (1995). Environmental Marketing Management: Meeting the Green Challenge, Pitman, London.

Piety, M.G. (2004). The long term: capitalism and culture in the new millennium. Journal of Business Ethics, 51, 103-118. 
INTERNATIONAL JOURNAL OF ACADEMIC RESEARCH IN BUSINESS AND SOCIAL SCIENCES

Vol. 9, No. 2, Feb, 2019, E-ISSN: 2222-6990 C 2019 HRMARS

Randola \& Fullerton (1994). Managing Diversity in an organization. New York:

Reinhardt, F.L. (1999). Bringing the environment down to the earth. Harvard Business Review, 149157

Robbins, S.P. \& Coulter, M. (1999). Management. $6^{\text {th }}$ Ed. London: Prentice hall International (UK) Limited.

Robin, D.P. \& Reidenbach, R.E. (1987). Social responsibility, ethics, and marketing strategy: closing the gap between concept and application. Journal of Marketing, 51, 44-58.

Rondinelli, D.A. (2003). Transnational corporations: international citizens or new sovereigns? Business Strategy Review, 14(4), 13-21

Shani, A.B. \& Lau, J.B. (2005). Behavior in Organizations: An Experiential Approach. ( $8^{\text {th }}$ ed). New York: McGraw-Hill Irwin.

Sheth, J.N. \& Parvatiyar, A. (1995). Ecological imperatives and the role of marketing in Polonsky, Mintu, M.J.

Stainer, A. (1997). Logistics - a productivity and performance perspective. Supply Chain Management, 2(2), 53-62.

Svensson, G. (2007; 2009). The transparency of SCM-ethics: conceptual framework and empirical illustrations. Supply Chain Management: An International Journal, 14(4), 259-269.

Svensson, G. \& Baath, H. (2008), "Supply chain management ethics: conceptual framework and illustration. Supply Chain Management: An International Journal, 14(3), 320-336.

Thom-Otuya, V.C \& Ubulom, W.J. (2002). Human Resources Engineering in Organization. Port Harcourt. Celwil Nigeria Ltd.

Whawell, P. (1998). The ethics of pressure groups. Business Ethics. European Review, 7(3). 